\title{
Complex vascular and orthopaedic limb injuries
}

Complex vascular injuries of the limbs, once almost exclusively encountered on the battlefield, are increasingly prevalent in civilian life, inevitable consequences of the proliferation of motor vehicles, progressive industrialisation, urban violence and terrorism. Penetrating trauma from low-velocity weapons usually results in localised disruption of vessels but the transient cavitational effect of the energy dissipated laterally from a high-velocity missile is to produce damage far beyond its trajectory. Blunt trauma from road accidents is much more common and, as it usually occurs at high velocity, the injuries are severe and involve all the tissues of the limb, avulsing arteries, veins and nerves, shattering bones, dislocating joints, and producing loss of muscle and skin. Such wounds are usually contaminated and there is a very high probability of associated injuries to the head, chest and abdomen. The patient is typically a young man and the vascular injury is to main vessels adjacent to a fracture. Common examples are the supracondylar fracture of the humerus, the comminuted fracture of the femur, fracture dislocation of the knee and type III open tibial fracture. The amount of softtissue injury reflects the severity of the wounding force.

The limb salvage rate after arterial injuries is much lower when they are associated with fractures of the long bones, but this difference is in part attributable to the simultaneous damage to soft tissues, the increased predisposition to infection and the delay in diagnosis. Striated muscle, deprived of its main blood supply, can tolerate 'warm ischaemia' for about six to eight hours but the time depends on the level of injury and the availability of collateral vessels. It varies also with the degree of generalised shock and vasoconstriction, and therefore cannot be predicted exactly. Tissue hypoperfusion and hypoxia increase capillary permeability which may raise compartment pressures and further attenuate blood flow, initiating a cycle of unfavourable events including smallvessel thrombosis, Volkmann's contracture, ischaemic nerve palsy, muscle necrosis, and sepsis. Delayed or missed diagnosis of vascular injury in association with an obvious fracture will invite these sequelae which presage loss of the limb. Evidence for the destructive potential of oxygen-derived free radicals and other substances produced in ischaemic tissue is accumulating, the greatest harm being inflicted during restoration of blood flow into a highly permeable vascular bed, a process termed post-ischaemic or reperfusion injury. It is

A. A. B. Barros D'Sa, MD, FRCS, FRCS Ed, Vascular Surgeon Vascular Surgery Unit, Royal Victoria Hospital, Grosvenor Road, Belfast BT12 6BJ, Northern Ireland.

(C) 1992 British Editorial Society of Bone and Joint Surgery $0301-620 X / 92 / 2383 \$ 2.00$

J Bone Joint Surg [ Br] 1992; 74-B: 176-8. in this context that the management of coincident vascular and orthopaedic limb injuries should be appraised. It is the subject of two interesting papers in this issue (page 181 and page 189) which describe the experience at centres with widely differing resources.

Time is the crucial arbiter of outcome and must be used profitably from the outset, ideally by swift transfer to hospital, efficient resuscitation and immediate operative treatment. It is also the main alterable factor in the equation which determines the survival of the injured limb. The efficient use of time necessitates the coordinated application of orthopaedic and vascular surgical skills.

The classical 'hard' clinical signs of arterial injury, such as poor or absent distal pulses, pallor, arterial bleeding and a pulsatile haematoma, are universally recognised but greater alertness and experience are required to perceive the subtle 'soft' signs of impaired circulation. This requires a constant awareness of the proximity of blood vessels to fractured bones and a careful search for evidence of transient ischaemia, the non-expanding haematoma, and the minimal neurological deficit.

An audible Doppler signal in the distal part of the limb may be mistakenly interpreted by the inexperienced as evidence of an intact proximal artery, and comparison of Doppler pressure measurements with those in the contralateral limb may not be practicable in seriously injured limbs, particularly in multiply-injured patients. The competence of angiography in localising arterial injury, and in excluding it, is well established and it is of particular value in penetrating wounds. With the exception of very minor signs of vascular injury a positive angiogram makes exploration mandatory; a negative result gives the confidence not to intervene and reduces the risk of unnecessary explorations. The surgeon who has no access to angiography is compelled to rely on clinical acumen to detect the presence of vascular injury and will inevitably register a higher incidence of negative explorations and missed vascular injuries. Biplane films, delineating the vascular lesion and possibly demonstrating extravasation, enable surgeons to plan their approach.

If ischaemia persists after reduction of a fracture, a hesitant or expectant attitude, based on a hopeful diagnosis of 'spasm', may be a recipe for disaster. Delay in requesting angiography may have serious consequences, and the medicolegal implications are obvious. The very high incidence of occult vascular damage in association with dislocations and fracture-dislocations of the knee should warrant a policy of routine angiography in these injuries. Angiography may also be more widely used to exclude arterial thrombosis secondary to limb injury in elderly atherosclerotic patients. In deft hands it 
carries a very small risk of major complications and, if angiography is available, it would be imprudent to forego the chance to confirm or deny the suspicion of vascular injury when clinical signs are equivocal.

While speed in diagnosis is essential, undue haste to repair the vessel can also be responsible for lapses in the application of sound surgical principles. Efforts to repair the artery before stabilising the bone may encourage the use of flawed and less desirable techniques such as lateral suture or end-to-end anastomosis under tension, sometimes at the cost of ligating useful collateral branches. In a climate of urgency, vital venous channels may be ligated and, more importantly, the manipulation of bone fragments during reduction may disrupt a delicately completed reconstruction. If the fracture is reduced first the vascular repair can be undertaken more safely, but the awareness that reduction and fixation of fractures is time consuming may persuade the orthopaedic surgeon into a hurried and technically inadequate bone fixation.

Temporary bridging of the injured artery and vein by intraluminal shunts solves the problem and can improve the quality of operative management by encouraging a logical and disciplined sequence of manoeuvres by the vascular and the orthopaedic surgeons. After exposure and control of bleeding, the ends of the injured vessels should be excised, followed by balloon thrombectomy and infusion of heparinised saline into the distal artery. An indwelling shunt, rejoining the ends of the artery, immediately halts the noxious effects of ischaemia and revitalises the limb, buying time for a considered approach to the rest of the operation. In situations of extensive soft-tissue destruction involving lengthy segments of vessels, long outlying shunts may be used to keep the distal limb alive. In the multiply-injured patient, limb vessels can be exposed and shunted by a vascular surgeon working unobtrusively alongside other specialists occupied with life-saving surgery elsewhere in the body. Shunting of an injured vein ensures adequate drainage of the distal limb, particularly if other channels are damaged. The blood in the distal veins should first be flushed out since it has a low $\mathrm{pH}$ and a high concentration of potassium and toxic metabolites likely to endanger the myocardium. If the main vein is simply clamped, the flow of blood into the limb through an intact or shunted artery may cause a perilous rise in compartment pressures.

Any of the many commercially available shunts may be used, or a suitable length of plastic or silicone elastomer tubing, of fine calibre with smoothly trimmed ends to avoid damage to the intima. The use of the shunt allows the situation to be surveyed, nerves to be identified, non-viable tissue to be debrided, and the wound to be cleaned and irrigated. Reperfusion sharpens the distinction between viable and dead tissue and makes possible more precise debridement. After accurate restoration of skeletal integrity, by external or internal fixation, the realigned limb is ready for the definitive vascular repair which, when completed, will remain undisturbed.
Neither artery nor vein need receive priority if both vessels have been shunted, and vascular reconstruction is no longer the customary race against the clock. There is time to harvest vein grafts and, if necessary, to fashion either a panel or a spiral compound vein graft to match the size of the host vessel. Precise suturing is facilitated by the shunt which acts as a stent. In cases of very extensive damage an extra-anatomical vein bypass graft, which passes through undamaged tissue at a distance from the wound may be constructed. It is good practice to obtain an angiogram on the operating table to confirm the adequacy of every arterial repair.

The few encouraging reports of the use of prosthetic grafts such as polytetrafluoroethylene should not induce complacency or obscure the risks of infection when they are used in injured limbs. A prosthesis may, however, be the preferred conduit when substantial tissue loss leaves inadequate cover for a vein graft which is then liable to break down.

A few patients may be lucky enough not to be harmed by ligation of a main vein, but in others massive oedema may result which can progress to gangrene and amputation, while yet others will develop chronic oedema and symptoms of obstructive venous insufficiency. At least one major venous channel should, therefore, be reconstructed using an autogenous vein graft.

It may be safe to close the incisions used for treating vascular complications of closed injuries but contaminated wounds should be left open, for delayed primary suture in five to seven days. This timing is of critical importance. Early closure is needed for uncomplicated healing, and it can only be achieved if previous debridement has been thorough. Cover for the repaired vessels may require swinging of a muscle such as sartorius or gracilis, and porcine heterografts have been used for temporary cover. Rotation of muscle flaps or the use of free vascularised muscular-cutaneous flaps require the skills of a plastic surgeon.

The use of temporary shunts usually keeps compartment pressures within an acceptable range; this significantly reduces the need for fasciotomy which can be assessed clinically by measurement of the compartment pressures. If in doubt, fasciotomy should be carried out immediately and adequately. In the upper limb, extensor and flexor compartments are decompressed, the flexor fasciotomy being continued into the palm of the hand. All four compartments of the lower leg can be effectively decompressed through skin incisions medially and laterally, and the destructive operation of fibulectomy is not required.

All the key manoeuvres in the vital operative sequence involving the use of temporary vascular shunts are contained in the simple alliterative aide-mémoire: stanch the bleeding, snip the vessels, scoop out the clot, syringe in the heparinised saline, shunt both artery and vein, survey the wound and identify nerve injury, perform scission of soft tissue, squirt saline to irrigate the wound, 
stabilise the bones, stitch the graft, if required swing tissue for cover, suture the wound or leave it open for delayed primary suture, and finally split the fascia to release muscle compartments if necessary (Fig. 1). The rationale for this sequence of steps is easily comprehended and its validity has been borne out by over 12 years of surgical practice.

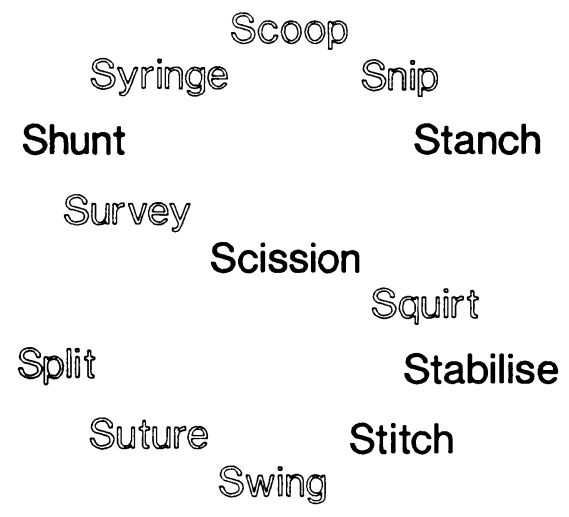

Postoperative antibiotic therapy, anticoagulation and maintenance of a good fluid balance are essential adjuvant measures. Mannitol can decrease compartment hypertension and inactivate oxygen-derived free radicals which are involved in reperfusion injury. Inspection of the wound under anaesthesia and further debridement may be necessary and postoperative peripheral flow observations by Doppler ultrasound are helpful. If graft failure is suspected, immediate angiography is recommended as a prelude to re-exploration.

Advances in pre-hospital care, resuscitation, angiography, external fixation, intraluminal shunting and techniques of vascular repair, all of which have improved the chances of limb salvage, may sometimes be responsible for over-optimism in treating irreparably mutilated limbs. Over-zealous attempts to preserve the limb commit the patient to the distress of multiple operations and anaesthetics, prolonged hospitalisation, probable sepsis, delayed rehabilitation and the disappointment of a late amputation. In appropriate cases, primary amputation is in the patient's best interest. Scoring systems have been proposed in an attempt to discriminate between the irretrievably damaged and the potentially salvageable extremity, using objective clinical criteria for the orthopaedic, vascular, soft-tissue and nerve injuries to the limb and for injuries elsewhere in the body. In practice, however, none of the reasons for delayed post-traumatic amputation, which broadly include failed vascular repair, sepsis, limb insensitivity and dysaesthesia, can be foreseen accurately at the time of admission. The decision to proceed to primary amputation should not be undertaken lightly, particularly in a young patient, and consultation and discussion with experienced colleagues often helps.

A. A. B. BARROS D'SA

\section{BIBLIOGRAPHY}

Allen MJ, Nash JR, Ioannidies TT, Bell PRF. Major vascular injuries associated with orthopaedic injuries to the lower limb. Ann $R$ Coll Surg Engl 1984; 66:101-4.

Barros D'Sa AAB The rationale for arterial and venous shunting in the management of limb vascular injuries. Eur J Vasc Surg 1989; $3: 471-4$.

Barros D'Sa AAB. Upper and lower limb vascular trauma. In: Greenhalgh RM, ed. Vascular surgical techniques. London: Ballière Tindall, 1989:47065.

Barros D'Sa AAB. How do we manage acute limb ischaemia due to trauma. In: Greenhalgh RM, Jamieson CW, Nicolaides AN, eds. Limb salvage and amputation for vascular disease. London: Saunders, 1988:135-50.

Barros D'Sa AAB, Hassard TH, Livingston RH, Irwin JW. Missileinduced vascular trauma. Injury 1980; 12:13-20.

Barros D'Sa AAB, Moorehead RJ. Combined arterial and venous intraluminal shunting in major trauma of the lower limb. Eur J Vasc Surg 1989; 3:577-81.

Bishara RA, Pasch AR, Lim LT, et al. Improved results in the treatment of civilian vascular injuries associated with fractures and dislocations. J Vasc Surg 1986; 3:707-11.

Eger M, Golcman L, Goldstein A, et al. The use of the temporary shunt in the management of arterial vascular injuries. Surg Gynaecol Obstet 1971; 132:67-70.

Elliott JRM, Templeton J, Barros D'Sa AAB. Combined bony and vascular limb trauma: a new approach to treatment. $J$ Bone Joint Surg [Br] 1984; 66-B:281.

Granger DN, Höllwarth ME, Parks DA. Ischemia-reperfusion injury role of oxygen-derived free radicals. Acta Physiol Scand [Suppl] $1986 ; 548: 47-63$.

Gregory RT, Gould RJ, Peclet M, et al. The mangled extremity syndrome (MES): a severity grading system for multisystem injury of the of the extremity. $J$ Trauma 1985; 25:1147-50.

Johansen K, Bandyk D, Thiele B, Hansen ST Jr. Temporary intraluminal shunts: resolution of a management dilemma in complex vascular injuries. J Trauma 1982; 22:395-402.

Johansen K, Daines M, Howey T, Helfet D, Hansen ST Jr. Objective criteria accurately predict amputation following lower extremity trauma. J Trauma 1990; 30:568-73.

Lange RH, Bach AW, Hansen ST Jr, Johansen KH. Open tibial fractures with associated vascular injuries: prognosis for limb salvage. $J$ Trauma $1985 ; 25: 203-8$

McCormick TM, Burch BH. Routine angiographic evaluation of neck and extremity injuries. $J$ Trauma $1979 ; 19: 384-7$.

McCoy GF, Hannon DG, Barr RJ, Templeton J. Vascular injury associated with low-velocity dislocation of the knee. $J$ Bone Joint Surg [Br] 1987; 69-B :285-7.

McNamara JJ, Brief DK, Stremple JF, et al. Management of fractures with associated arterial injury in combat casualties. J Trauma $1873 ; 13: 17-9$.

Menzoian JO, Doyle JE, Cantelmo NL, LoGerfo FW, Hirsch E. A comprehensive approach to extremity vascular trauma. Arch Surg $1985 ; 120: 801-5$.

Mubarak SJ, Owen CA. Double-incision fasciotomy of the leg for decompression in compartment syndromes. J Bone Joint Surg [Am] 1977; 59-A:184-7.

Rich NM, Baugh JH, Hughes CW. Acute arterial injuries in Viet Nam J Trauma 1970; 10:359-69.

Rose SC, Moore EE. Trauma angiography: the use of clinical findings to improve patient selection and case preparation. J Trauma 1988 28:240-5.

Shah DM, Naraynsingh V, Leather RP, Corson JD, Karmody AM. Advances in the management of acute popliteal vascular blunt injuries. J Trauma $1985 ; 25: 793-7$.

Smith RF, Szilagyi DE, Elliott JP. Fracture of long bones with arterial injury due to blunt trauma. Arch Surg 1969; 99:315-24.

Snyder WH III, Thal ER, Bridges RA, Gerlock AJ, Perry MO, Fry WJ. The validity of normal arteriography in penetrating trauma. Arch Surg 1978; $113: 424-6$.

Weaver FA, Rosenthal RE, Waterhouse G, Adkins RB. Combined skeletal and vascular injuries of the lower extremities. Am J Surg $1984 ; 50: 189-97$ 